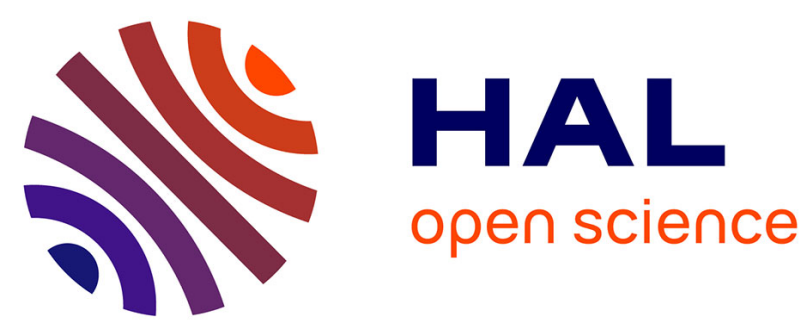

\title{
How Does Masticatory Muscle Architecture Covary with Mandibular Shape in Domestic Dogs?
}

Colline Brassard, Marilaine Merlin, Elodie Monchâtre-Leroy, Claude

Guintard, Jacques Barrat, Cécile Callou, Raphael Cornette, Anthony Herrel

\section{- To cite this version:}

Colline Brassard, Marilaine Merlin, Elodie Monchâtre-Leroy, Claude Guintard, Jacques Barrat, et al. How Does Masticatory Muscle Architecture Covary with Mandibular Shape in Domestic Dogs? Evolutionary Biology, 2020, 47 (2), pp.133-151. 10.1007/s11692-020-09499-6 . hal-02984503

\section{HAL Id: hal-02984503 \\ https://hal.science/hal-02984503}

Submitted on 31 Oct 2020

HAL is a multi-disciplinary open access archive for the deposit and dissemination of scientific research documents, whether they are published or not. The documents may come from teaching and research institutions in France or abroad, or from public or private research centers.
L'archive ouverte pluridisciplinaire HAL, est destinée au dépôt et à la diffusion de documents scientifiques de niveau recherche, publiés ou non, émanant des établissements d'enseignement et de recherche français ou étrangers, des laboratoires publics ou privés. 
3 Colline Brassard ${ }^{1,2, *}$, Marilaine Merlin ${ }^{1}$, Elodie Monchâtre-Leroy ${ }^{3}$, Claude Guintard ${ }^{4,5}$, 4 Jacques Barrat $^{3}$, Cécile Callou ${ }^{2}$, Raphaël Cornette ${ }^{6}$, Anthony Herrel ${ }^{1}$.

$5 \quad{ }^{1}$ UMR 7179 Mécanismes Adaptatifs et Evolution (CNRS, MNHN), Muséum national 6 d'Histoire naturelle, 55 rue Buffon, Paris, France.

$7{ }^{2}$ Archéozoologie, archéobotanique : sociétés, pratiques et environnements (AASPE),

8 Muséum national d'Histoire naturelle, CNRS, CP55, 57 rue Cuvier 75005 Paris, France

$9{ }^{3}$ ANSES, Laboratoire de la rage et de la faune sauvage, Station expérimentale d'Atton, 10 Malzéville, France.

$11{ }^{4}$ Laboratoire d'Anatomie comparée, Ecole Nationale Vétérinaire, de l'Agroalimentaire et de 12 l'Alimentation, Nantes Atlantique - ONIRIS, Nantes Cedex 03, France.

${ }^{5}$ GEROM, UPRES EA 4658, LABCOM ANR NEXTBONE, Faculté de santé de l'Université d'Angers, France.

${ }^{6}$ UMR 7205 Institut de Systématique, Evolution, Biodiversité (CNRS, MNHN, UPMC, EPHE), Muséum national d'Histoire naturelle, Paris, France.

* Corresponding author: colline.brassard@mnhn.fr 
Despite the considerable scientific interest in the variability and patterns of integration in the dog skull, how these patterns impact or are driven by function remains largely unexplored. Since the mandible is directly involved in mastication, it can be expected to be directly related to the development of the adductor and abductor muscles. Here, we explore whether variation in the architecture and size of the masticatory muscles is associated with the variation in mandibular shape in dogs. We obtained muscle data from the dissection of 48 dogs from different breeds and morphotypes to explore the architecture of the muscles and used 3D geometric morphometric approaches to quantify the shape of the mandible. Covariations between the masticatory muscles and mandibular shape were explored using two-block partial least square analyses (2B-PLS). Our results show there is a strong covariation between mandibular shape and masticatory muscles mass (rPLS from 0.70 to 0.74 for the first axis representing more than $90 \%$ of the total covariance) and physiological cross-sectional area (rPLS from 0.64 to 0.73 for the first axis representing more than $80 \%$ of the total covariance), irrespective of whether size is taken into account or not. These results suggest muscle size and thus attachment area requirements for individual muscles are likely drivers of mandibular shape. Moreover, mandible shape is likely to be a good predictor of muscle force. Finally, it appears that domestication of dogs has not resulted in a disuse phenotype characterized by a decoupling between form and function.

Key words: dog; geometric morphometrics; jaw muscle; mandible; masticatory system 


\section{Introduction}

As a consequence of several thousand years of artificial selection and inbreeding, the domestic dog has the highest variability in skull shape within the Carnivora (Drake and Klingenberg 2010; Selba et al. 2019) and encompasses over 400 breeds according to kennel clubs. The shapes extend beyond the variability of wild species (Drake and Klingenberg 2010), varying from elongated and narrow skull shapes (dolichocephalic) to short and wide (brachycephalic) skulls. This diversification is the result of a slight relaxation of natural and functional selection pressures (Drake et al. 2015, 2017; Curth et al. 2017), but more importantly, depends on anthropogenic selection pressures driven by aesthetic considerations or the selection of animals for particular skills such as hunting or defense (Drake and Klingenberg 2008).

The genetic mechanisms underlying this diversity are well known (Fondon and Garner 2004; Bannasch et al. 2010; Boyko et al. 2010; Marchant et al. 2017). For example, the mutation of BMP3 has been shown to be involved in brachycephaly (Schoenebeck et al. 2012). Integration and modularity have also been extensively studied within the skull and even the mandible (Drake and Klingenberg 2010; Meloro et al. 2011; Curth et al. 2017; Curth 2018; Machado et al. 2018; Selba et al. 2019). However, the functional impact of this extraordinary variability in shape has received less attention in dogs (but see Ström et al. 1988; Endo et al. 1999; Koch et al. 2003; Ellis et al. 2008, 2009). Given that artificial selection can have indirect functional consequences in wild canids such as the red fox (Trut 1999; Trut et al. 2009; Dugatkin 2018), and since these selection pressures are strong, the resulting morphological changes may have occurred extremely rapidly (Johnston and Selander 1964; Reznick et al. 1997; Hendry and Kinnison 1999; Huey et al. 2000; Grant and Grant 2006; Trut et al. 2009; Dugatkin 2018). In most vertebrates species variation in the shape of the skull and the mandible is linked to variation in the jaw adductor muscles (Watt and Williams 1951; He and Kiliaridis 2003; Cornette et al. 2013; Cornette, Tresset, Houssin, et al. 2015; Fabre et al. 2018). Indeed, the jaw adductors and abductors and the skull and mandible are parts of the same functional unit with bones providing skeletal struts and levers that are moved by the forces generated by muscles (Frost and Schönau 2000; Herring et al. 2001; Frost 2003). In addition to the need for providing muscular attachment, bones are also modified due to the loads imposed by muscle contraction in addition to external forces such as bite and joint forces (Frost 2001, 2003; 
Schoenau 2005; Sharir et al. 2011; Brotto and Bonewald 2015). For the jaw system to function, the muscles and bones need to be coordinated to achieve effective mastication and biting. As such the system can be expected to be functionally integrated (Olson and Miller 1951; Van Valen 1965; Klingenberg 2014). The quantitative interplay between jaw muscles and the bones of the skull remains poorly described in domestic dogs (but see Liebman and Kussick, 1965), in contrast to other mammals (Crompton 1963; Weijs and Hillen 1986; Hylander et al. 1992, 1998; Herring et al. 2001; Lieberman et al. 2004; Ross and Metzger 2004; Ross et al. 2005; Herring 2007; Ravosa et al. 2007, 2016; Bourke et al. 2008; Cornette et al. 2013; Cornette, Tresset, and Herrel 2015; Penrose et al. 2016; Fabre et al. 2018) rendering our understanding of the functional consequences of the tremendous morphological variation in the skull of domestic dogs limited.

Prior studies of in vivo bite forces and jaw-muscle electromyography in dogs (Lindner et al. 1995; Ellis et al. 2008; Kim et al. 2018), as well as estimations obtained from the dry-skull method (Thomason 1991; Ellis et al. 2009) have suggested that differences in morphology are related to differences in bite force, mainly because of space constraints around the skull, and because of differences in the length of the in and out-levers of the masticatory apparatus. However, no study has focused on the architecture of the jaw muscles (fiber length, pennation angle or muscle mass) in domestic dogs rendering estimates of bite force difficult. In the dry skull method, the three-dimensional architecture of the jaw muscles is not incorporated (Schumacher 1961; Miller et al. 1965; Thomason 1991; Ellis et al. 2009), which can result in underestimates of maximal bite force.

The great morphological diversity present in the cranium of dogs provides a unique opportunity to understand the relationships between morphological variation and muscle development. Moreover, understanding these relationships would permit better inferences on the functional impact of selection in dogs. Here we focus on the mandible as this bone is implicated in a single function: mastication. We expect there to be a direct link between muscle attachment area and jaw shape, that means, in other words, significant covariations between jaw muscles architecture (mass and physiological cross-sectional area) and mandibular shape. However, as recent dog breeds have been selected largely for aesthetic reasons, we predict that these covariations are likely low. Finally, as the posterior part of the mandible both serves as the area for muscle insertion and is more strongly impacted by the 
need for muscle attachement, we expect patterns of covariation to be stronger for the mandibular ramus. 


\section{Specimens}

104

105

Specimens were obtained from the Veterinary School of Nantes (France), the Veterinary School of Maisons Alfort (France), and the laboratory of rabies and wildlife disease studies in Nancy - Anses (France). The dataset is composed of the mandibles of 59 dogs (Canis lupus familiaris) from various breeds (Table 1, see Supplementary material Table S1 for details). The breeds were estimated based on their similarity to existing standards, but crossbreeding is important and as such these animals may not represent 'pure' breeds. Because accurate ages were unknown, we estimated ages based on tooth wear, bone texture, and the aspect of the cranial sutures (degree of closure). The two dogs in the group 'A' (a beagle and a bull terrier) represent the youngest individuals with molars still erupting, a very porous mandible and unclosed cranial sutures (4-6 months according to Barone, 2010). The beagle in group ' $\mathrm{B}$ ' has its spenobasilar suture still open ( $<8-10$ months for the dog according to Barone, 2010) and the mandible is still porous. The 22 individuals from the group ' $\mathrm{D}$ ' are older, with a closed interfrontal suture and worn denture (>3-4 years). The 33 other dogs, from the group ' $\mathrm{C}$ ', are intermediate adults (from 10 months to 3 years). We chose to keep the youngest individuals in our analyses to increase the morphological variability in the sample. There is no geriatric dog.

\section{Dissections}

Specimens were either dissected when still fresh or frozen and then defrosted (48 dogs). If preserved in formol, the head was not dissected but directly prepared for shape analyses (an additional 11 beagles). Dissection of the constituent bellies of the jaw adductor muscles were done in accordance with the description provided by Penrose et al. (2016), following the nomenclature of previous authors (Turnbull 1970; Ström et al. 1988; Tomo et al. 1993; Druzinsky et al. 2011). However the anterior and posterior parts of the zygomaticomandibularis were separated and the digastric was dissected as well. Since the lateral pterygoid is very small in carnivores (Turnbull 1970; Herring 2007; Penrose et al. 2016), we considered medial and lateral pterygoids as one single muscle mass.

The following muscles were removed layer by layer: the digastric (Dig), the superficial masseter (MS), the deep masseter (MP), the anterior part of the zygomaticomandibularis 
(ZMA), the posterior part of the zygomaticomandibularis (ZMP), the suprazygomatic part of the temporalis (SZ), the superficial temporalis (TS), the deep temporalis (TP), and the pterygoids $(\mathrm{P})$. The origins and insertions of the nine muscle layers dissected are illustrated in Fig. 1 and described in Supplementary material Table S2.

\section{Quantification of jaw muscles architecture}

After dissection, all muscle divisions were weighed using a digital scale (Mettler Toledo AE100). Fiber length and pennation angles were measured directly on the muscle after sectioning the muscles along their line of action. Several measurements were taken for each measurement at different location in the muscle, and we used the mean for our calculations. The reduced Physiological Cross-Section Area (PCSA), which represents a proxy of the intrinsic strength of the muscles, was calculated for each muscle muscle following the definition of Haxton (1944), and using a muscle density of 1,06 g/cm3 (Méndez and Keys 1960).

We used the following formula: PCSA $=\frac{\text { mass }(\mathrm{g}) * \cos (\text { angle of pennation }(\mathrm{rad}))}{1,06\left(\mathrm{~g} . \mathrm{cm}^{-3}\right) * \text { fiber length }(\mathrm{cm})}$.

\section{Photogrammetry}

After dissection, bones were cleaned and dried. One hundred photographs per right hemimandible were taken while turning around the specimen (Fau et al. 2016). Photos were taken using a Nikon D5500 Camera (24,2 effective megapixels) with a 60mm lense. The Agisoft PhotoScan software (@ 2014 Agisoft LLC, 27 Gzhatskaya st., St. Petersburg, Russia) was used for the 3D reconstructions of the mandibles.

\section{Landmarking and geometric morphometrics}

Geometric morphometric analysis was used to quantify patterns of morphological variation. Twenty-five homologous anatomical landmarks and 190 sliding semilandmarks on curves were placed on each specimen using the software Landmark version 3.0.0.6 (C) IDAV 20022005; Wiley et al. 2005). Landmark locations are provided in Fig. 2 and Table 2.

A template was also created following the method of Cornette et al. (2013) to patch 185 slinding semilandmarks on the mandible surface of all specimens (Fig. 2). The three- dimensional coordinates for all sets of landmarks were then imported into $\mathrm{R}$ version 3.6.0 (2019-04-26). The Morpho package (version 2.7) implemented in R (Schlager 2013) 
was used for most of the following analyses. A 3D sliding semilandmark procedure (Bookstein 1997; Gunz et al. 2005) was performed. According to this iterative procedure, sliding semilandmarks on surfaces are projected from the template onto each specimen using a thin plate spline deformation (Klingenberg et al. 2002; Gunz et al. 2005; Schlager 2012, 2013). Next, landmarks are slid iteratively while minimizing the bending energy. All sliding semilandmarks were constrained by homologous landmarks (Gunz et al. 2005) and allowed to slide along the predefined curves and surfaces. The sliding semilandmarks are consequently transformed into spatially homologous landmarks. Landmarks coordinates of all specimens can then be compared using traditional geometric morphometric methods.

\section{Variability in mandibular shape and jaw muscles}

A Generalized Procrustes Analysis (GPA - Rohlf and Slice, 1990) was performed using the function procSym (Klingenberg et al. 2002; Gunz et al. 2005; Dryden and Mardia 2016). The importance and significance of the correlations between mandibular shape and centroid size and between muscle morphology (PCSA and mass) and centroid size were explored using the function "cor.test". Allometry-free coordinates and visualisations were obtained using the functions "CAC" (Mitteroecker et al. 2004) and "showPC". Allometry-free coordinates of $\log _{10}$-transformed muscle data were calculated using the function " $1 \mathrm{~m}$ ". Principal Component Analyses (PCA) were performed using the function "prcomp" based on the coordinates of all aligned specimens, on allometry-free coordinates, on the PCSA of all muscles, on the scaled PCSA of all muscles, on muscle mass and, on scaled muscle mass. The deformation of the mandible of a beagle to the consensus of the GPA was used as a reference for all further visualisations. The beagle was chosen because it was the dog that was closest to center of the PCA describing variation in mandibular shape.

\section{Covariations between mandible shape and jaw muscles}

To explore the patterns of covariation between the mandibular shape and the PCSA or mass of the jaw muscles, we performed a two-block partial least square analyses (2B-PLS) with the function "pls2B" (Rohlf and Corti, 2000). We did not consider phylogeny (Parker et al. 2004) in our analyses because we had no indication of pure race membership. 
2B-PLS calculates singular values and creates new axes by looking for linear combinations in each block that maximise the covariance between blocks (the variation of PCSA or mass of all the muscles and mandibular shape). For each axis a PLS coefficient is generated (intensity of the covariation) and p-values are calculated by comparing the singular value to those obtained from 1000 permuted blocks (significance of the covariation).

The mandibular ramus is likely to be more closely associated with space constraints related to the volume of jaw muscles than the mandibular body. To test whether the covariation was higher between muscles and the ramus of the mandible only, we explored both covariations with the complete mandible shape, and with a subset of landmarks and sliding semilandmarks of curves representing the posterior part of the mandible only.

A total of twelve 2B-PLS analyses were conducted: mandibular shape - PCSA, mandibular shape - scaled PCSA, allometry-free mandibular shape - scaled PCSA, ramus shape - PCSA, ramus shape - scaled PCSA, allometry-free ramus shape - scaled PCSA, mandibular shape mass, mandibular shape - scaled mass, allometry-free mandibular shape - scaled mass, ramus shape - mass, ramus shape - scaled mass, allometry-free ramus shape - scaled mass.

A Z-score was finally calculated to compare PLS coefficients with the function "compare.pls" from the package geomorph. 


\section{Variability in mandibular shape}

208

Results of the Principal Component Analyses and correlation tests for exploring allometries are detailed in Supplementary material Table S3.

The first two axes of the PCA represents $46.1 \%$ of the variability in mandibular shape. The next axes each represent a very small part of the total variability ( $8.9 \%$ for axis 3 ). Only the morphological variations related to axis 1 and axis 2 - that are the most informative - will therefore be described (Fig. 3). The mandibular shape varies greatly depending on the morphotype, and variation is also important within a single breed (beagles). Especially noticeable is the variation in robustness, the shape of the coronoid process, and the ventral curvature of the mandibular body. Along the first axis of the PCA, the molossoid/brachycephalic dogs are generally opposed to dolichocephalic/lupoid dogs. The first axis is mainly explained by differences in size $(\mathrm{r}=0.51 ; \mathrm{P}<0.001)$ with the biggest mandibles being positioned to right of the scatterplot. Mesocephalic and dolichocephalic dogs are not clearly distinguishable and overlap towards the left part of the scatterplot. Most of these morphological changes are explained by size, since allometry is moderately strong $\left(\mathrm{R}^{2}=0.44 ; \mathrm{P}<0.001\right.$, Fig. S1). Molossoid dogs - which most often correspond to large mandible sizes - have shorter and more robust and laterally curved mandibles, with more developed coronoid, condylar, and angular processes. The rostral part of the mandible is more ventrally curved and the condyle tends to be at a straight angle to the sagittal plane in molossoid dogs (Figs 3A, S1). Variation along axis two is observed for dogs of the same breed, as is the case for the Beagle which occupies the entire upper left quadrant of the scatterplot. This variation is not related to size $(\mathrm{P}>0.05)$ and describes the rostro-ventral curvature of the mandible and the orientation of the coronoid process. The two first axes are not correlated with the age of the dogs $(\mathrm{P}>0.05)$. The PCA performed on allometry-free shapes (Fig. 3B) show that dolichocephalic and brachycephalic dogs oppose themselves along the first axis with the mesocephalic dogs at the very center. The variation along this axis involves the ventral and lateral curvature of the mandibular body, the width of the coronoid process and the relative size of the condyle and angular processes. The two youngest dogs are included in the same morphospace as the adults. Interestingly, the "juvenile" bull terrier is located in the same part of the scatterplot as the other molossoid dogs when analyses are 
performed on allometry-free shapes (Fig. 3B). The "juvenile" Beagle remains positioned close to the adult Beagles.

\section{Variability in jaw muscle architecture}

Muscle data are given in Supplementary material Table S1 and the results of the statistical analyses (PCA and correlation tests exploring allometries) are detailed in Supplementary material Table S3.

The angles of pennation are around $0^{\circ}$ in the digastric, $30-40^{\circ}$ in the temporalis and masseter and $40^{\circ}$ in the pterygoids. Muscles from the temporal complex have very long muscle fibers (up to $60 \mathrm{~mm}$; mean around $30 \mathrm{~mm}$ ) compared to muscles from the masseteric and pterygoid complexes (up to $30 \mathrm{~mm}$; mean around $15-20 \mathrm{~mm}$ ). The temporal complex represents $64 \%$ $(\min =55 \% ; \max =71 \%)$ of the total volume and $50 \%(\min =40 \%$; $\max =61 \%)$ of the total PCSA of the adductor muscles. The masseteric complex represents $27 \%(\min =22 \%$; $\max =32 \%)$ of the total volume and $36 \%$ ( $\min =29 \%$; $\max =46 \%$ ) of the total PCSA of the adductor muscles. The pterygoid complex represents only $9.6 \%(\min =6 \% ; \max =13 \%)$ of the total volume and $14 \%(\min =6 \% ; \max =24 \%)$ of the total PCSA of the adductor muscles. The mass of the lateral pterygoid muscles represents only around $7 \%$ of the mass of the pterygoid complex in the domestic $\operatorname{dog}(\min =2.5 \%$; $\max =20.4 \%)$ and $0.67 \%$ of the total mass of the adductor muscles $(\min =0.20 \% ; \max =2.4 \%)$.

Whereas the mass and PCSA of jaw muscles vary greatly depending on breeds, significant variation is also observed among Beagles. Their morphological space stretches along axis 1 , but mainly along axis 2. Since similar results were observed for mass and PCSA, only the PCA with muscle PCSAs will be described here (Fig. 4). The PCA with muscle masses is available in the supplementary material (Supplementary Fig. S2).

The first axis of the PCA performed on the raw or scaled PCSA (representing 76.5\% or 51.3\% of the total variation, respectively) or mass data ( $91.7 \%$ for raw mass and $71.8 \%$ for scaled mass) loads strongly with the temporalis and masseter muscles. The second axis of the same analyses explains only a small amount of the total variation (PCSA: 5.5\% for raw data and $10.5 \%$ for scaled data; mass: $2.3 \%$ for raw data and $7.5 \%$ for scaled data), and is driven by variation in the anterior part of the zygomaticomandibularis and the temporalis pars 
suprazygomatica, for our analyses of PCSA, or by variation in the masseter group (above all the anterior part of the zygomaticomandibularis) for the PCA on mass.

The PCAs with raw muscle data reflect differences in the size of the head. Molossoid dogs most often with larger heads - have more powerful jaw muscles than most of the other dogs. On the opposite, dogs from the Toy group (Chihuahua, Papillon) - characterized by very small heads - have the smaller and less forceful muscles. Statistical analyses showed that the variation in muscle volume and force is strongly corelated to variation in mandibular size (mass: $\mathrm{r}=0.89, \mathrm{P}<0.001$; PCSA: $\mathrm{r}=0.83, \mathrm{P}<0.001$ ).

The PCAs performed on scaled PCSA and scaled mass show that the dogs with biggest and strongest jaw muscles for their size are large molossoid dogs, represented by a Leonberg, an American Staffordshire, Mastiffs, a Cane corso, and more markedly the two Rottweillers, the Pitbull and the two Bulldogs. Surprisingly, the Chihuahua in our sample also has very strong and voluminous muscles for its size and is positioned close to the Cane Corso, the Rottweiler and the American stafforshire. The hunting and shepherds dogs (including the German Shepherd), the Papillon and the Boxers of our sample have medium to low muscle masses and rather weak muscles for their size. The Cavalier King Charles has masticatory muscle masses that are larger than the average of our sample when corrected for differences in size (close to the Cane Corso) but muscle strength is not impacted. Although the small sample size and the low intra-breed diversity of our sample does not allow us to draw conclusions about breedspecific diversity our results suggest that this would a fruitful avenue for further research.

\section{Covariation between mandibular shape and jaw muscle architecture}

A summary of the results of the 2B-PLS is given in Table 3. Detailed results are available in Supplementary material Table S4. Only the main results are detailed below.

The covariation between mandibular shape and the masticatory muscles is highly significant, whether size is taken into account or not (Table 3). The coefficients of covariation are high, and they do not significantly differ between muscle masses and muscle PCSAs, and between scaled and raw muscle data. The coefficients of covariation obtained for the shape of the ramus only are not higher than the ones for the complete mandible. 
Here we focus on the covariations between mandibular shape and the scaled muscle data, since the centroid size is an important driver of covariation (but see supplementary material for further visualisations and results for the raw data: Figs S3 to S6). The covariation between scaled PCSA and mandibular shape was significant (Fig. 5), for the first PLS axis (PCSA: PLS1 $88 \%$ of the covariance, rPLS1=0.64, P<0.001). Similar results were observed for scaled masses (PLS-1 95\% of the covariance, $r P L S 1=0.70, P<0.001$, Zscore $=0.75 ; \mathrm{P}=0.23$, Supplementary Fig. S7). The first PLS axis (accounting for $88 \%$ of the covariance) shows that lupoid, graioid and bracoid dogs are situated at the positive part of the scatterplot and oppose molossoid breeds at the negative part of the scatterplot. All muscles strongly covary with mandibular shape. The positive part of the scatterplot corresponds to the breeds with a low PCSA of these muscles and a gracile mandible with a strait and flat body that curves outward, a higher ventral part of the ramus, a thin, reduced and slightly tilted outwards coronoid process with a shallow masseteric fossa, a small condyle and a small and straight angular process. Dogs at the negative part of the scatterplot have robust mandibles with a very ventrally curved and thick body, a lower ventral part of the ramus, a taller coronoid process with a deep masseteric fossa, and a large, medially and caudally extended and less mediolateraly oblique condyle.

The covariations between scaled muscle data and ramus shape are significant only on secondary axes, explaining less than $16 \%$ of the covariance. The 2B-PLS between the mandible ramus shape and the scaled masses of the jaw muscles (PLS-2 21\% of covariation, r-PLS2 $=0.63, \mathrm{P}=0.006$, Fig. 6) shows that dogs with more voluminous deep masseter muscles and less voluminous temporal muscles and superficial masseters for their size have a more curved coronoid process with a deeper masseteric fossa and a lower and less curved angular process (and vice versa). Similar results were observed for the third axis of the 2B-PLS between ramus shape and the scaled PCSA (Supplementary Fig. S8) and for the second axis of the 2B-PLS between allometry-free ramus shape and scaled masses (Supplementary Fig. S9).

Similar results were observed for allometry-free mandibular shape and scaled PCSA (Fig. 7) or scaled mass (Fig. S9). Changes in the body of the mandible along the first PLS axis are the same as those previously described except some more specific anatomical features for the coronoid process. For a given size of the coronoid process dogs with less forceful muscles 
325 have a more caudally curved and narrower coronoid process (with a shallower masseteric 326 fossa) contrary to dogs with stronger muscles which have a wider and thicker coronoid 327 process (with a deeper masseteric fossa).

328 Significant covariations between allometry-free shape of the mandible ramus and scaled 329 masses show that a more caudally curved coronoid process and a less pronounced and curved 330 angular process are related to proportionally more developed deep masseter muscles and a 331 proportionally less developed superficial masseter muscle (Fig. S10). 


\section{Variations in mandibular shape and masticatory muscles}

334

The general shape of the mandibular ramus and the relative importance of masticatory muscles in dogs reflects the specialization towards vertical movements as in other canids. Indeed, the condyle is cylinder-shaped, mediolaterally elongated, curved backwards, and at a right angle to the sagittal plane. Moreover, the temporal and masseteric complexes responsible for the vertical movements of the jaw are by far the most strongly developed in canids since they represent around $90 \%$ of the mass and intrinsic strength of the adductor muscles. This corroborates descriptions of previous authors (Schumacher 1961; Turnbull 1970; Noble 1973; Ström et al. 1988). The pterygoid muscles - that have a more medio-lateral line of action - are small and the shape of the condyle permits only limited medio-lateral rotational movements that function to bring the blades of the carnassials into close contact (Ström et al. 1988; Ewer 1998). The lateral pterygoid is very small (it represents less than 3\% of the of the total mass of the adductor muscles) and its role is ambiguous because it could be involved in both mandibular protraction and adduction (Turnbull 1970; Tomo et al. 1993; Evans and DeLahunta 2010).

The proportions in volume and PCSA of the different muscles were not the same. For example, even though the pterygoid complex always represents less than $13 \%$ of the total mass of the adductor muscles, it can represents up to $24 \%$ of the total intrinsic strength of the adductor muscles, indicating that these muscles are optimized for force production. This is because muscles with longer fibers (temporal) are in proportion 'disadvantaged' compared to muscles with shorter fibers (pterygoids or masseter). This reflects an architectural trade-off between PCSA and fiber length: a muscle cannot be optimized for both force production and contraction velocity (Gans and Bock 1965; Taylor and Vinyard 2013). The PCSA data provided here are further of interest as they may provide better estimations of bite force than estimations obtained from models using the 'dry-skull' method (Thomason 1991; Ellis et al. 2009). However, muscle PCSAs are only general proxies of maximal intrinsic muscle force. Muscle loads on the mandible will also depend on the size and position of the attachment sites of the jaw muscles on the skull and mandible, on the unbalanced and uncomplete recruitment of the muscle during biting (Kim et al. 2018), and on the nature of the muscle fibers (Grünheid et al. 2009; Kim et al. 2018). 
Extreme variation has already been demonstrated for the skull (Drake and Klingenberg 2010; Selba et al. 2019) and is generally considerd to be the result of intensive dog breeding and artificial selection for aesthetic reasons. Our study demonstrates that the masticatory muscles and the shape of the mandible also show important variation related to variation in the size of the individuals and the type of breed. Breeds represented by several individuals, such as Beagles, also showed unexpected levels of variation. Although we had too few young individuals to assess the effect of ontogeny this is also likely to contribute to the overall diversity in both mandible shape and muscle architecture.

The different muscle layers show an important diversity in mass, but also in intrinsic muscle strength due to the great variation in fiber length and pennation angles (Supplementary material Table S1), making the architecture of the jaw muscles complex. Our results indicate that the masticatory muscles scale isometrically relative to mandibular size, which corroborates the results of Penrose et al. (2016). The molossoid dogs of our sample generally have the strongest and most voluminous muscles. On the contrary, the dogs from the Toy group of our sample (the Chihuahua, the King Charles and the Papillon) have very small muscles, logically resulting in a lower intrinsic force generation capacity. However our analyses suggest that some dogs of very small breeds such as the Chihuahua - the smallest breed recognized by kennel clubs - tend to have muscles that are as imposing and as powerful as those of some specimens of Cane Corso, Rottweiller or American Staffordshire when size is taken into account. However, the low intrabreed diversity in our sample does not allow us to explicitly test for differences between breeds. Future studies are needed to explore this further. In our study, the only German Shepherd is included within the variability of the other shepherd dogs in our sample, with less voluminous and powerful muscles irrespective of variation in size. As stated above, our sample does not allow to draw conclusions on breedspecific diversity but it would be interesting to test whether German Shepherd dogs are grouped with other shepherd dogs or with breeds dedicated to protection . Indeed, the German Shepherd is a very "multi-skilled" breed, that has been modified as an army or police dog but that was originally designed to be a working sheepherder (Parker et al. 2004).

\section{Relations between mandibular shape and the development of masticatory muscles}

As predicted, we found significant covariation between the shape of the mandible and the development of the masticatory muscles irrespective of whether size is taken into account or 
not. This study logically suggests that there is a strong association between muscle volume and mandibular form. The coefficient of covariation of the 2B-PLS with allometry-free shape and/or scaled muscle data is not different from the 2B-PLS on raw data and remains elevated. Therefore, size alone is not enough to explain the existing covariation. The dispersion of the individuals along the PLS axis for the 2B-PLS with scaled muscle data (Fig. 5-7, Supplementary Fig. S7-S10) shows, however, that similar mandibular morphologies can correspond to different relative muscle volumes or strength. For example, among the three dogs from the Toy group of our sample, the Chihuahua and the Papillon have very similar mandibular shapes but the Chihuahua dog has much more powerful and voluminous muscles than the Papillon when size is removed. This suggests significant differences in muscle architecture among dogs with similar morphotypes.

Morphological changes that appear directly related to muscle volume and strength involve areas of insertion of the masticatory muscles: the size and shape of the coronoid process, the depth of the masseteric fossa and the size and curvature of the angular process. This suggests that the attachment area requirements for individual muscles likely drive mandibular shape. Muscle volume and strength are also related to changes in general features, such as the robustness of the mandible, the ventral and lateral curvature of the body and the size of the condyle. Surprisingly, covariations are not significantly different when considering the posterior part of the mandible only relative to the entire mandible. This suggests that the curvature and thickness of the body where no muscles attach and which bears the dental alveoli, also covaries with the shape of the ramus. Indeed, the body and the ramus together form an integrated system adapted to the mechanical constraints of biting and chewing. The shape associated with low (scaled or not scaled) muscle masses and PCSAs is characterised by a relatively long and flat body, a small coronoid process curved at its posterior tip, a shallow masseteric fossa, and a small and ventromedial oblique condyle. On the contrary, shapes related to large and strong muscles correspond to robust mandibles with a relatively large, wide coronoid process with a deep masseteric fossa, a laterally and ventrally curved ramus, and a (medially) long and large condyle. All these changes can be explained by muscle volume, conditioning the space available for those muscles and responses to loading of the mandible at the teeth. Accordingly, for dogs with big and strong muscles (mainly large brachycephalic dogs), the mandible is more curved in the medio-lateral plane. This temporomandibular joint axis rotation has been described by Curth et al. (2017) and interpreted as a 
result of reduced space availability in short-faced skulls. However, this could also be a mechanical adaptation to the volume occupied by the temporal and masseter muscles. An inclined mandible is more suite to allow large muscles to pass between the skull and the mandible and goes hand-in-hand with wider zygomatic arches in brachycephalic breeds. The slightly opposing orientations of the coronoid process and mandibular body (medially inclined condyle and body anteriorly curved outwards in dolichocephalic dogs) seem to reflect a compromise in shape to distribute the forces exerted on the mandible, allowing both muscle attachement and vertical opening/closing movements. Thus the change in the angle between the coronoid process and the condyle could be a mechanical response to the reaction forces and important for joint stabilisation.

All muscles covary together on the first axis of the 2B-PLS with the complete mandible (explaining more than $80 \%$ of the covariation; Figs $5,7, \mathrm{~S} 3, \mathrm{~S} 4, \mathrm{~S} 7, \mathrm{~S} 9$ ) but the secondary axis of the 2B-PLS performed with the mandible ramus only (explaining up to $20 \%$ of the covariation; Fig. 6, Supplementary Figs S5, S6, S8, S10) allowed us to describe more specific variations. We observed that the more the superficial masseter, the temporal complex and the pterygoid muscles were developed, the straighter the coronoid process was. On the opposite, the bigger the deep masseter and zygomaticomandibularis, the more caudally curved the coronoid process. Liebman and Kussick (1965) described variation in the morphology of the mandible depending on the removal of the temporal or masseter on one side of the head of a dog. They report that the variation in shape of the angular process is likely to be due to variation in both the pterygoid and masseter muscles. Indeed, the angular process tended to be straight rather than curved when the masseter muscle was removed. This description is consistent with our observations (Figs 6, S8, S10). For these authors, the shape of the coronoid process is more probably linked to the temporal muscle. They observed that the coronoid process tended to be straighter after removing the temporal muscle, whereas on the normal side the coronoid process was more caudally oriented. Our own observations, however, do not support these results (Figs 6, S8, S10). This could be due to a balance between the masseteric and temporal complexes. Liebman and Kussick (1965) completely removed one of the two complexes so their observations do not take these interactions into account. In our 2B-PLS showing opposing loadings (Figs 6, S8, S10), both complexes play a role in the construction of the PLS-1 axis. The less developed the temporal complex is, the more developed the deep masseter, including the zygomaticomandibularis. As the 
zygomaticomandibularis anterior inserts mainly on the anterior part of the masseteric fossa to the tip of the coronoid process, a bigger muscle would involve a more important surface area. This could explain why we observed more caudally curved coronoid process in dogs with a relatively more imposing zygomaticomandibularis.

However, our study did not allow to explore the mechanical relations between mandible shape and muscle loading per se. Further investigations would be needed to explore the connection between bone resistance and muscle force through, for example, finite element analyses (e.g. Bourke et al. 2008; Kim et al. 2018; Penrose et al. under review). An interesting and complementary approach may be to investigate the link between mandible shape and bone cortical thickness and its degree of biomineralization to track functional variation according to load resistance (Ross et al. 2005; Kupczik et al. 2007; Rayfield 2007; Cox et al. 2015). Indeed, even though the shape of the mandible is the combined result of phylogeny and developmental constraints, its shape also depends on mechanical loading (Weijs and Hillen 1986; Wolff 1986; Hannam and Wood 1989; Raadsheer et al. 1999; Currey 2002, 2003; Daegling and Hotzman 2003; Mavropoulos et al. 2004; Ravosa et al. 2007; Sharir et al. 2011; Slizewski et al. 2013). Furthermore, it has been shown that the relationship between bone morphology and muscle force is reciprocal, as the shape of a bone determines the load that it can tolerate (Weiner and Wagner 1998; Frost 2001). As a result, the mandible is plastic: it is constantly modeled throughout life to be able to resist the changes in the mechanical environment, that is the muscle forces and external forces exerted upon it during chewing (Frost 2001; Currey 2002; Fabre et al. 2018). Accordingly, it has been demonstrated that increased physical activity affects the geometry and composition of bones, whereas decreased loads due to enforced rest or muscle dysfunctions result in thinner bones (Schoenau 2005; Ward et al. 2006). Among other external constraints, diet is likely to play a significant role in mandible shape. We had no information about the diet of the individuals in our sample, but further studies exploring the influence of food texture on mandible shape and the mechanical properties of the cortical bone of the mandible would be of interest. Indeed, it has been demonstrated that food mechanical properties influence cortical bone modelling and remodelling (Bouvier and Hylander 1981, 1984; Lieberman et al. 2004; Ionova-Martin et al. 2011; Scott et al. 2014a, 2014b; Ravosa et al. 2015, 2016). The study of Scott et al (2014a) on rabbits lead them to suggest that mammals may be very plastic even at late life-history stages. All these elements might explain the observed differences among the different dogs in our 
study (Bouvier and Hylander 1981, 1984). Moreover it would be interesting to study how pathologies that impact muscle development (dysplasia and jaw locking) affect mandible shape (Robins and Grandage 1977; Johnson 1979; Thomas 1979; Hoppe and Svalastoga 1980; Ström et al. 1988). Indeed, according to He and Kiliaridis (2003), the alteration of masticatory muscle function can affect the morphology of certain regions of the skull and face in ferrets. Additionnaly, we could not explore the role of ontogeny because we had too few juveniles to test for the effect of age. Future studies could explore the evolution of the interplay between bone and jaw muscles in dogs through postnatal development, as it has been done in other mammals (Swiderski and Zelditch 2013). Indeed, muscle provides growth factors for bone tissue throughout postnatal development independently of forces imparted to bones. This can significantly impact bone formation at attachment areas and might thus be a source of the observed patterns of covariation between muscle size and the shape of the mandibular ramus.

\section{Domestication and integration in the masticatory apparatus}

As predicted, jaw muscle architecture covaries with mandibular shape, but we did not expect such a strong covariation.

Integration is produced by the sharing of biological processes such as the same developmental origin or the implementation of the same function (Olson and Miller 1951, 1958, 1999). This strong integration makes sense given that bone is a living and plastically remodelled tissue, causing changes in the shape of the mandible in direct response to muscle and jaw loading. However we expected the extreme diversity in shapes due to artificial selection to interfere with this functional integration, as many domestic dogs are not under strong functional constraints for chewing or biting. This is even more surprinsing as a low integration has been documented in strepsirrhine primates, which are, on the contrary, subject to strong natural selection and dietary constraints (Fabre et al. 2018).

We suggest that this strong integration is perhaps determined by a strong interaction between genes responsible for the mandibular shape and genes responsible for the development of jaw muscles. Muscle development would therefore be intrinsically linked to bone development. Consequently, selection on morphology would therefore produce a correlated response in the functional abilities (Cheverud 1982; Klingenberg 2010, 2014). Muscles and bones indeed 
share common genetic determinants (Karasik and Kiel 2008; Blank 2014) and cells derive from a common mesenchymal precursor. Multiple loci overlapping between the two traits and several genes with possible pleiotropic effects on both bones and muscles have been indentified (Kaji 2014). As a consequence, it is possible that some genes may trigger changes in bone anatomy, and as a result, affect muscle architecture (Karasik and Kiel 2008). It is also plausible that slight changes of systemic control factors occurs during development and impact both muscle and bone (e.g., small modulations of the growth hormone; Karasik and Kiel, 2008). Genetic muscle disorders provide an opportunity to learn how muscle and bone interact. For example, a myostatin deficiency (growth differentiation factor 8 [GDF8]) is observed in the whippet dog breed (Mosher et al. 2007) and results in a 'bully' whippet, with an approximate doubling of muscle mass and resulting in more robust bones. Observed allometries in muscle data and covariations between muscle data and shape supports the genetic influence on both bone and muscle, as well as integration (Karasik and Kiel 2010). However, more investigations on the genetic and molecular interplay between jaw muscles and the mandible are needed to better understand the drivers of variation in the masticatory apparatus.

Morover, our study seems to suggest that dogs show different patterns of integration according to their function. Breeds first selected for hunting or herding differ from the dogs that were first selected for human or herd protection. It seems that the selection for different biting abilities has resulted in different patterns of integration. Further studies focusing on a much larger sample are, however, needed to investigate whether dog breed selection is related to specialisations towards specific patterns of covariation between muscle and bones.

Our results raise the question of whether artificial selection produces a reorganization of the integration patterns in order to allow morphological traits to vary, as proposed by Hanot et al. (2018). Karasik and Kiel (2010) suggested that natural selection tends to favour alleles whose pleiotropic effects contribute to the attainment of appropriate proportions between muscles and bones, and the pattern of covariation is expected to evolve to match fitness demands. As a consequence, one would expect stronger integration among wild species since it responds to environmental selection pressures driving the jaw system towards an 'optimum' corresponding to the ecological context, and resulting in less morphological variability, especially for the wolf (Curth et al. 2017). We had no wolves in our sample which would be 
551 essential to test this hypothesis, but comparing our results with those non-domestic canids

552 could help understand whether the phenotypic diversification of dogs is responsible for a

553 change in integration pattern, and how integration may constrain changes in morphology or 554 jaw muscle development. 
556

557

558

559

560

561

562

563

564

565

566

567

568

569

570

571

572

573

574

575

576

577

578

579

580

581

582

Our study assessed the impact of the dramatic variation in mandible shape in domestic dogs on the development and architecture of the masticatory muscles. Our results suggest that jaw muscles and mandible shape form a highly integrated system in dogs. This could be the consequence of genes controlling both muscle and bone development, as well as epigenetic effects driving variation in muscles and bones (Iinuma et al. 1991) or the interaction between genetic mecanisms and plasticity (Hanot et al. 2017). Our results provide a better understanding of jaw function in dogs which despite its general interest remains rather poorly understood (Ellis et al. 2008, 2009). To further test whether mandibular form is driven by attachment area requirements and/or load resistance, finite element approaches may be of interest. The strong integration of the lower jaw offers the possibility to infer the functional consequences of morphological changes in fossil or archaeological specimens. Despite this strong integration, the question remains wether integration is stronger in wild or commensal canids, and whether domestication has lead to a disruption of the natural integration between form and function as suggested previously.

\section{Acknowledgements}

We thank the Veterinary school ONIRIS-Nantes (France) and Anses (Nancy, France) for providing dog heads for dissection. We are grateful to Manuel Comte, Mickaël Godet and Frederic Lebatard for their help in managing specimens and their helpful discussions about the preparation of the skulls. We also thank Arnaud Delapré for his help with photogrammetry and Fabien Belhaoues for his constructive feedback on a first draft of this manuscript. We thank two anonymous reviewers who contributed to the improvement of an earlier version of this manuscript by their valuable comments and suggestions.

\section{Funding}

This research was funded by the Ministère de l'Enseignement supérieur, de la Recherche et de l'Innovation.

\section{Conflict of interest}

The authors declare that they have no conflicts of interest. 


\section{References}

Bannasch, D., Young, A., Myers, J., Truvé, K., Dickinson, P., Gregg, J., et al. (2010). Localization of canine brachycephaly using an across breed mapping approach. PloS One, 5(3), e9632. https://doi.org/10.1371/journal.pone.0009632

Barone, R. (2010). Anatomie comparée des mammifères domestiques : Tome 1, Ostéologie (5e édition.). Paris: Vigot.

Blank, R. D. (2014). Bone and Muscle Pleiotropy: The Genetics of Associated Traits. Clinical reviews in bone and mineral metabolism, 12(2), 61-65. https://doi.org/10.1007/s12018-014-9159-4

Bookstein, F. L. (1997). Morphometric tools for landmark data: geometry and biology. Cambridge University Press.

Bourke, J., Wroe, S., Moreno, K., McHenry, C., \& Clausen, P. (2008). Effects of gape and tooth position on bite force and skull stress in the dingo (Canis lupus dingo) using a 3dimensional finite element approach. PLoS One, 3(5), e2200. https://doi.org/10.1371/journal.pone.0002200

Bouvier, M., \& Hylander, W. L. (1981). Effect of bone strain on cortical bone structure in macaques (Macaca mulatta). Journal of Morphology, 167(1), 1-12. https://doi.org/10.1002/jmor.1051670102

Bouvier, M., \& Hylander, W. L. (1984). The effect of dietary consistency on gross and histologic morphology in the craniofacial region of young rats. American Journal of Anatomy, 170(1), 117-126. https://doi.org/10.1002/aja.1001700109

Boyko, A. R., Quignon, P., Li, L., Schoenebeck, J. J., Degenhardt, J. D., Lohmueller, K. E., et al. (2010). A Simple Genetic Architecture Underlies Morphological Variation in Dogs. PLOS Biology, 8(8), e1000451. https://doi.org/10.1371/journal.pbio.1000451

Brotto, M., \& Bonewald, L. (2015). Bone and muscle: Interactions beyond mechanical. Bone, 80, 109-114. https://doi.org/10.1016/j.bone.2015.02.010

Budras, K.-D. (Ed.). (2007). Anatomy of the dog (5., rev. ed.). Hannover: Schlüter.

Cheverud, J. M. (1982). Phenotypic, Genetic, and Environmental Morphological Integration in the Cranium. Evolution, 36(3), 499-516. https://doi.org/10.1111/j.15585646.1982.tb05070.x

Christiansen, P., \& Adolfssen, J. S. (2005). Bite forces, canine strength and skull allometry in carnivores (Mammalia, Carnivora). Journal of Zoology, 266(2), 133-151. https://doi.org/10.1017/S0952836905006643

Cornette, R., Baylac, M., Souter, T., \& Herrel, A. (2013). Does shape co-variation between the skull and the mandible have functional consequences? A 3D approach for a 3D problem. Journal of Anatomy, 223(4), 329-336. https://doi.org/10.1111/joa.12086

Cornette, R., Tresset, A., \& Herrel, A. (2015). The shrew tamed by Wolff's law: do functional constraints shape the skull through muscle and bone covariation? Journal of Morphology, 276(3), 301-309. https://doi.org/10.1002/jmor.20339

Cornette, R., Tresset, A., Houssin, C., Pascal, M., \& Herrel, A. (2015). Does bite force provide a competitive advantage in shrews? The case of the greater white-toothed 
shrew. Biological Journal of the Linnean Society, 114(4), 795-807. https://doi.org/10.1111/bij.12423

Cox, P. G., Rinderknecht, A., \& Blanco, R. E. (2015). Predicting bite force and cranial biomechanics in the largest fossil rodent using finite element analysis. Journal of Anatomy, 226(3), 215-223. https://doi.org/10.1111/joa.12282

Crompton, A. W. (1963). The Evolution of the Mammalian Jaw. Evolution, 17(4), 431-439. https://doi.org/10.2307/2407093

Currey, J. D. (2002). Bones: structure and mechanics. (Princeton University Press.). https://doi.org/10.1515/9781400849505

Currey, J. D. (2003). How Well Are Bones Designed to Resist Fracture? Journal of Bone and Mineral Research, 18(4), 591-598. https://doi.org/10.1359/jbmr.2003.18.4.591

Curth, S. (2018). Modularity and Integration in the Skull of Canis lupus (Linnaeus 1758): A Geometric Morphometrics Study on Domestic Dogs and Wolves, 78.

Curth, S., Fischer, M. S., \& Kupczik, K. (2017). Can skull form predict the shape of the temporomandibular joint? A study using geometric morphometrics on the skulls of wolves and domestic dogs. Annals of Anatomy - Anatomischer Anzeiger, 214, 53-62. https://doi.org/10.1016/j.aanat.2017.08.003

Daegling, D. J., \& Hotzman, J. L. (2003). Functional significance of cortical bone distribution in anthropoid mandibles: an in vitro assessment of bone strain under combined loads. American Journal of Physical Anthropology, 122(1), 38-50. https://doi.org/10.1002/ajpa.10225

Drake, A. G., Coquerelle, M., \& Colombeau, G. (2015). 3D morphometric analysis of fossil canid skulls contradicts the suggested domestication of dogs during the late Paleolithic. Scientific Reports, 5, 82-99. https://doi.org/10.1038/srep08299

Drake, A. G., Coquerelle, M., Kosintsev, P. A., Bachura, O. P., Sablin, M., Gusev, A. V., et al. (2017). Three-Dimensional Geometric Morphometric Analysis of Fossil Canid Mandibles and Skulls. Scientific Reports, 7(1), 9508. https://doi.org/10.1038/s41598017-10232-1

Drake, A. G., \& Klingenberg, C. P. (2008). The pace of morphological change: historical transformation of skull shape in St Bernard dogs. Proceedings. Biological sciences, 275(1630), 71-76. https://doi.org/10.1098/rspb.2007.1169

Drake, A. G., \& Klingenberg, C. P. (2010). Large- Scale Diversification of Skull Shape in Domestic Dogs: Disparity and Modularity. The American Naturalist, 175(3), 289-301. https://doi.org/10.1086/650372

Druzinsky, R. E., Doherty, A. H., \& De Vree, F. L. (2011). Mammalian Masticatory Muscles: Homology, Nomenclature, and Diversification. Integrative and Comparative Biology, 51(2), 224-234. https://doi.org/10.1093/icb/icr067

Dryden, I. L., \& Mardia, K. V. (2016). Statistical Shape Analysis: With Applications in R. John Wiley \& Sons. 10.1002/9781119072492

Dugatkin, L. A. (2018). The silver fox domestication experiment. Evolution: Education and Outreach, 11(1), 16. https://doi.org/10.1186/s12052-018-0090-х

Ellis, J. L., Thomason, J. J., Kebreab, E., \& France, J. (2008). Calibration of estimated biting forces in domestic canids: comparison of post- mortem and in vivo measurements. 
Journal of Anatomy, 212(6), 769-780. https://doi.org/10.1111/j.14697580.2008.00911.x

Ellis, J. L., Thomason, J., Kebreab, E., Zubair, K., \& France, J. (2009). Cranial dimensions and forces of biting in the domestic dog. Journal of Anatomy, 214(3), 362-373. https://doi.org/10.1111/j.1469-7580.2008.01042.X

Endo, H., Taru, H., Nakamura, K., Koie, H., Yamaya, Y., \& Kimura, J. (1999). MRI Examination of the Masticatory Muscles in the Gray Wolf (Canis lupus), with Special Reference to the M. temporalis. Journal of Veterinary Medical Science, 61(6), 581586. https://doi.org/10.1292/jvms.61.581

Evans, H. E., \& DeLahunta, A. (2010). Guide to the dissection of the dog (7th ed.). St. Louis, Mo: Saunders/Elsevier.

Ewer, R. F. (1998). The Carnivores. Cornell University Press.

Fabre, A.-C., Perry, J. M. G., Hartstone-Rose, A., Lowie, A., Boens, A., \& Dumont, M. (2018). Do Muscles Constrain Skull Shape Evolution in Strepsirrhines? The Anatomical Record, 301(2), 291-310. https://doi.org/10.1002/ar.23712

Fau, M., Cornette, R., \& Houssaye, A. (2016). Photogrammetry for 3D digitizing bones of mounted skeletons: Potential and limits. Comptes Rendus Palevol, 15(8), 968-977. https://doi.org/10.1016/j.crpv.2016.08.003

Flahive, M. A. (2015). Evaluating Muscle Fiber Architecture. Master's thesis, University of South Carolina. https://scholarcommons.sc.edu/etd/3632

Fondon, J. W., \& Garner, H. R. (2004). Molecular origins of rapid and continuous morphological evolution. Proceedings of the National Academy of Sciences, 101(52), 18058. https://doi.org/10.1073/pnas.0408118101

Frost, H. M. (2001). From Wolff's law to the Utah paradigm: Insights about bone physiology and its clinical applications. The Anatomical Record, 262(4), 398-419. https://doi.org/10.1002/ar.1049

Frost, H. M. (2003). Bone's mechanostat: a 2003 update. The Anatomical Record Part A: Discoveries in Molecular, Cellular, and Evolutionary Biology: An Official Publication of the American Association of Anatomists, 275(2), 1081-1101. https://doi.org/10.1002/ar.a.10119

Frost, H. M., \& Schönau, E. (2000). The" muscle-bone unit" in children and adolescents: a 2000 overview. Journal of pediatric endocrinology and metabolism, 13(6), 571-590. https://doi.org/10.1515/JPEM.2000.13.6.571

Gans, C., \& Bock, W. J. (1965). The functional significance of muscle architecture--a theoretical analysis. Ergebnisse Der Anatomie Und Entwicklungsgeschichte, 38, 115142.

Grant, P. R., \& Grant, B. R. (2006). Evolution of character displacement in Darwin's finches. Science (New York, N.Y.), 313(5784), 224-226. https://doi.org/10.1126/science.1128374

Grünheid, T., Langenbach, G. E. J., Korfage, J. A. M., Zentner, A., \& van Eijden, T. M. G. J. (2009). The adaptive response of jaw muscles to varying functional demands. European Journal of Orthodontics, 31(6), 596-612. https://doi.org/10.1093/ejo/cjp093 
Gunz, P., Mitteroecker, P., \& Bookstein, F. L. (2005). Semilandmarks in Three Dimensions. In D. E. Slice (Ed.), Modern Morphometrics in Physical Anthropology (pp. 73-98). Boston, MA: Springer US. https://doi.org/10.1007/0-387-27614-9_3

Hamrick, M. W., McNeil, P. L., \& Patterson, S. L. (2010). Role of muscle-derived growth factors in bone formation. Journal of Musculoskeletal \& Neuronal Interactions, 10(1), 64-70.

Hannam, A. G., \& Wood, W. W. (1989). Relationships between the size and spatial morphology of human masseter and medial pterygoid muscles, the craniofacial skeleton, and jaw biomechanics. American Journal of Physical Anthropology, 80(4), 429-445. https://doi.org/10.1002/ajpa.1330800404

Hanot, P., Herrel, A., Guintard, C., \& Cornette, R. (2017). Morphological integration in the appendicular skeleton of two domestic taxa: the horse and donkey. Proceedings of the Royal Society B: Biological Sciences, 284(1864), 20171241. https://doi.org/10.1098/rspb.2017.1241

Hanot, P., Herrel, A., Guintard, C., \& Cornette, R. (2018). The impact of artificial selection on morphological integration in the appendicular skeleton of domestic horses. Journal of Anatomy, 232(4), 657-673. https://doi.org/10.1111/joa.12772

Hartstone-Rose, A., Perry, J. M. G., \& Morrow, C. J. (2012). Bite Force Estimation and the Fiber Architecture of Felid Masticatory Muscles. The Anatomical Record, 295(8), 1336-1351. https://doi.org/10.1002/ar.22518

Haxton, H. A. (1944). Absolute muscle force in the ankle flexors of man. The Journal of physiology, 103(3), 267-273.

He, T., \& Kiliaridis, S. (2003). Effects of masticatory muscle function on craniofacial morphology in growing ferrets (Mustela putorius furo). European Journal of Oral Sciences, 111(6), 510-517. https://doi.org/10.1111/j.0909-8836.2003.00080.x

Hendry, A. P., \& Kinnison, M. T. (1999). Perspective: The Pace of Modern Life: Measuring Rates of Contemporary Microevolution. Evolution, 53(6), 1637-1653. https://doi.org/10.2307/2640428

Herring, S. W. (2007). Masticatory muscles and the skull: a comparative perspective. Archives of Oral Biology, 52(4), 296-299. https://doi.org/10.1016/j.archoralbio.2006.09.010

Herring, S. W., Rafferty, K. L., Liu, Z. J., \& Marshall, C. D. (2001). Jaw muscles and the skull in mammals: the biomechanics of mastication. Comparative Biochemistry and Physiology Part A: Molecular \& Integrative Physiology, 131(1), 207-219. https://doi.org/10.1016/S1095-6433(01)00472-X

Hoppe, F., \& Svalastoga, E. (1980). Temporomandibular dysplasia in American Cocker Spaniels. Journal of Small Animal Practice, 21(12), 675-678. https://doi.org/10.1111/j.1748-5827.1980.tb05960.x

Huey, R. B., Gilchrist, G. W., Carlson, M. L., Berrigan, D., \& Serra, § Luís. (2000). Rapid Evolution of a Geographic Cline in Size in an Introduced Fly. Science, 287(5451), 308. https://doi.org/10.1126/science.287.5451.308 
Hung, M.-L., Chou, C., Chen, C.-H., \& Own, Z.-Y. (2010). Learner readiness for online learning: Scale development and student perceptions. Computers \& Education, 55(3), 1080-1090. https://doi.org/10.1016/j.compedu.2010.05.004

Hylander, W. L., Johnson, K. R., \& Crompton, A. (1992). Muscle force recruitment and biomechanical modeling: an analysis of masseter muscle function during mastication in Macaca fascicularis. American Journal of Physical Anthropology, 88(3), 365-387. https://doi.org/10.1002/ajpa.1330880309

Hylander, W. L., Ravosa, M. J., Ross, C. F., \& Johnson, K. R. (1998). Mandibular corpus strain in primates: further evidence for a functional link between symphyseal fusion and jaw- adductor muscle force. American Journal of Physical Anthropology, 107(3), 257-271. https://doi.org/10.1002/(SICI)1096-8644(199811)107:3<257::AIDAJPA3>3.0.CO;2-6

Iinuma, M., Yoshida, S., \& Funakoshi, M. (1991). Development of masticatory muscles and oral behavior from suckling to chewing in dogs. Comparative biochemistry and physiology. A, Comparative physiology, 100(4), 789-794. https://doi.org/10.1016/0300-9629(91)90293-1

Ionova-Martin, S. S., Wade, J. M., Tang, S., Shahnazari, M., Ager, J. W., Lane, N. E., et al. (2011). Changes in cortical bone response to high-fat diet from adolescence to adulthood in mice. Osteoporosis international: a journal established as result of cooperation between the European Foundation for Osteoporosis and the National Osteoporosis Foundation of the USA, 22(8), 2283-2293. https://doi.org/10.1007/s00198-010-1432-x

Johnson, K. A. (1979). Temporomandibular joint dysplasia in an Irish Setter. Journal of Small Animal Practice, 20(4), 209-218. https://doi.org/10.1111/j.1748-5827.1979.tb06708.x

Johnston, R. F., \& Selander, R. K. (1964). House Sparrows: Rapid Evolution of Races in North America. Science, 144(3618), 548-550. https://doi.org/10.1126/science.144.3618.548

Kaji, H. (2014). Interaction between Muscle and Bone. Journal of bone metabolism, 21(1), 29-40. https://doi.org/10.11005/jbm.2014.21.1.29

Karasik, D., \& Kiel, D. P. (2008). Genetics of the Musculoskeletal System: A Pleiotropic Approach. Journal of Bone and Mineral Research, 23(6), 788-802. https://doi.org/10.1359/jbmr.080218

Karasik, D., \& Kiel, D. P. (2010). Evidence for pleiotropic factors in genetics of the musculoskeletal system. Bone, 46(5), 1226-1237. https://doi.org/10.1016/j.bone.2010.01.382

Kim, S. E., Arzi, B., Garcia, T. C., \& Verstraete, F. J. M. (2018). Bite Forces and Their Measurement in Dogs and Cats. Frontiers in Veterinary Science, 5. https://doi.org/10.3389/fvets.2018.00076

Klingenberg, C. P. (2010). Evolution and development of shape: integrating quantitative approaches. Nature Reviews. Genetics, 11(9), 623-635. https://doi.org/10.1038/nrg2829 
Klingenberg, C. P. (2014). Studying morphological integration and modularity at multiple levels: concepts and analysis. Philosophical Transactions of the Royal Society B: Biological Sciences, 369(1649), 20130249. https://doi.org/10.1098/rstb.2013.0249 Klingenberg, C. P., Barluenga, M., \& Meyer, A. (2002). Shape Analysis of Symmetric Structures: Quantifying Variation Among Individuals and Asymmetry. Evolution, 56(10), 1909-1920. https://doi.org/10.1111/j.0014-3820.2002.tb00117.x

Koch, D. A., Arnold, S., Hubler, M., \& Montavon, P. M. (2003). Brachycephalic Syndrome in Dogs. VetLearn.com, 25(1), 48-55.

Kupczik, K., Dobson, C., Fagan, M., Crompton, R., Oxnard, C., \& O’Higgins, P. (2007). Assessing mechanical function of the zygomatic region in macaques: validation and sensitivity testing of finite element models. Journal of Anatomy, 210(1), 41-53. https://doi.org/10.1111/j.1469-7580.2006.00662.x

Lieberman, D. E., Krovitz, G. E., Yates, F. W., Devlin, M., \& St. Claire, M. (2004). Effects of food processing on masticatory strain and craniofacial growth in a retrognathic face. Journal of Human Evolution, 46(6), 655-677. https://doi.org/10.1016/j.jhevol.2004.03.005

Liebman, F. M., \& Kussick, L. (1965). An Electromyographic Analysis of Masticatory Muscle Imbalance with Relation to Skeletal Growth in Dogs. Journal of Dental Research, 44(4), 768-774. https://doi.org/10.1177/00220345650440042401

Lindner, D., Marretta, S., Pijanowski, G., Johnson, A., \& Smith, C. (1995). Measurement of bite force in dogs: a pilot study. Journal of veterinary dentistry, 12(2), 49-52.

Machado, F. A., Zahn, T. M. G., \& Marroig, G. (2018). Evolution of morphological integration in the skull of Carnivora (Mammalia): Changes in Canidae lead to increased evolutionary potential of facial traits. Evolution, 72(7), 1399-1419. https://doi.org/10.1111/evo.13495

Marchant, T. W., Johnson, E. J., McTeir, L., Johnson, C. I., Gow, A., Liuti, T., et al. (2017). Canine Brachycephaly Is Associated with a Retrotransposon-Mediated Missplicing of SMOC2. Current biology: CB, 27(11), 1573-1584.e6. https://doi.org/10.1016/j.cub.2017.04.057

Mavropoulos, A., Kiliaridis, S., Bresin, A., \& Ammann, P. (2004). Effect of different masticatory functional and mechanical demands on the structural adaptation of the mandibular alveolar bone in young growing rats. Bone, 35(1), 191-197. https://doi.org/10.1016/j.bone.2004.03.020

Meloro, C., Raia, P., Carotenuto, F., \& Cobb, S. N. (2011). Phylogenetic signal, function and integration in the subunits of the carnivoran mandible. Evolutionary Biology, 38(4), 465-475. https://doi.org/10.1007/s11692-011-9135-6

Méndez, J. V., \& Keys, A. (1960). Density and composition of mammalian muscle. Metabolism-clinical and Experimental, 9, 184-188.

Miller, M. E., Christensen, G. C., \& Evans, H. E. (1965). Anatomy of the Dog. Academic Medicine, 40(4), 400.

Mitteroecker, P., Gunz, P., Bernhard, M., Schaefer, K., \& Bookstein, F. L. (2004). Comparison of cranial ontogenetic trajectories among great apes and humans. Journal of Human Evolution, 46(6), 679-698. https://doi.org/10.1016/j.jhevol.2004.03.006 
Mosher, D. S., Quignon, P., Bustamante, C. D., Sutter, N. B., Mellersh, C. S., Parker, H. G., \& Ostrander, E. A. (2007). A mutation in the myostatin gene increases muscle mass and enhances racing performance in heterozygote dogs. PLoS genetics, 3(5), e79-e79. https://doi.org/10.1371/journal.pgen.0030079

Noble, H. W. (1973). Comparative functional anatomy of temporomandibular joint. Oral Sciences Reviews, 2(0), 3-28.

Olson, E. C., \& Miller, R. L. (1951). A Mathematical Model Applied to a Study of the Evolution of Species. Evolution, 5(4), 325-338. https://doi.org/10.2307/2405677

Olson, E. C., \& Miller, R. L. (1958). Morphological integration. Chicago : University of Chicago Press.

Olson, E. C., \& Miller, R. L. (1999). Morphological Integration. University of Chicago Press. Parker, H. G., Kim, L. V., Sutter, N. B., Carlson, S., Lorentzen, T. D., Malek, T. B., et al. (2004). Genetic Structure of the Purebred Domestic Dog. Science, 304(5674), 11601164. http://www.jstor.org/stable/3836878

Penrose, F., Cox, P., Kemp, G., \& Jeffery, N. (under review). Functional morphology of the jaw adductor muscles in the Canidae. The Anatomical Record.

Penrose, F., Kemp, G. J., \& Jeffery, N. (2016). Scaling and Accommodation of Jaw Adductor Muscles in Canidae. The Anatomical Record, 299(7), 951-966. https://doi.org/10.1002/ar.23355

Raadsheer, M. C., van Eijden, T. M. G. J., van Ginkel, F. C., \& Prahl-Andersen, B. (1999). Contribution of Jaw Muscle Size and Craniofacial Morphology to Human Bite Force Magnitude. Journal of Dental Research, 78(1), 31-42. https://doi.org/10.1177/00220345990780010301

Ravosa, M. J., Kunwar, R., Stock, S. R., \& Stack, M. S. (2007). Pushing the limit: masticatory stress and adaptive plasticity in mammalian craniomandibular joints. Journal of Experimental Biology, 210(4), 628-641. https://doi.org/10.1242/jeb.02683

Ravosa, M. J., Menegaz, R. A., Scott, J. E., Daegling, D. J., \& McAbee, K. R. (2016). Limitations of a morphological criterion of adaptive inference in the fossil record. Biological Reviews of the Cambridge Philosophical Society, 91(4), 883-898. https://doi.org/10.1111/brv.12199

Ravosa, M. J., Scott, J. E., McAbee, K. R., Veit, A. J., \& Fling, A. L. (2015). Chewed out: an experimental link between food material properties and repetitive loading of the masticatory apparatus in mammals. PeerJ, 3. https://doi.org/10.7717/peerj.1345

Rayfield, E. J. (2007). Finite element analysis and understanding the biomechanics and evolution of living and fossil organisms. Annu. Rev. Earth Planet. Sci., 35, 541-576. https://doi.org/10.1146/annurev.earth.35.031306.140104

Reznick, null, Shaw, null, Rodd, null, \& Shaw, null. (1997). Evaluation of the Rate of Evolution in Natural Populations of Guppies (Poecilia reticulata). Science (New York, N.Y.), 275(5308), 1934-1937. https://doi.org/10.1126/science.275.5308.1934

Robins, G., \& Grandage, J. (1977). Temporomandibular joint dysplasia and open-mouth jaw locking in the dog. Journal of the American Veterinary Medical Association, 171(10), 1072-1076. 
Rohlf, F. J., \& Corti, M. (2000). Use of two-block partial least-squares to study covariation in shape. Systematic Biology, 49(4), 740-753. https://doi.org/10.1080/106351500750049806

Ross, C. F., \& Metzger, K. A. (2004). Bone strain gradients and optimization in vertebrate skulls. Annals of Anatomy - Anatomischer Anzeiger, 186(5), 387-396. https://doi.org/10.1016/S0940-9602(04)80070-0

Ross, C. F., Patel, B. A., Slice, D. E., Strait, D. S., Dechow, P. C., Richmond, B. G., \& Spencer, M. A. (2005). Modeling masticatory muscle force in finite element analysis: sensitivity analysis using principal coordinates analysis. The Anatomical Record Part A: Discoveries in Molecular, Cellular, and Evolutionary Biology: An Official Publication of the American Association of Anatomists, 283(2), 288-299. https://doi.org/10.1002/ar.a.20170

Schlager, S. (2012). Sliding semi-landmarks on symmetric structures in three dimensions. Presented at the The 81st Annual Meeting of the American Association of Physical Anthropologists, Portland, OR, Anthropology, University of Freiburg, Germany.

Schlager, S. (2013). Soft-tissue reconstruction of the human nose : population differences and sexual dimorphism.

Schoenau, E. (2005). From mechanostat theory to development of the 'Functional MuscleBone-Unit'. J Musculoskelet Neuronal Interact, (3), 232-238.

Schoenebeck, J. J., Hutchinson, S. A., Byers, A., Beale, H. C., Carrington, B., Faden, D. L., et al. (2012). Variation of BMP3 Contributes to Dog Breed Skull Diversity. PLoS Genetics, 8(8), e1002849. https://doi.org/10.1371/journal.pgen.1002849

Schumacher, G.-H. (1961). Funktionelle Morphologie der Kaumuskulatur. Jena: Fischer.

Scott, J. E., McAbee, K. R., Eastman, M. M., \& Ravosa, M. J. (2014a). Teaching an old jaw new tricks: diet-induced plasticity in a model organism from weaning to adulthood. Journal of Experimental Biology, 217(22), 4099-4107. https://doi.org/10.1242/jeb.111708

Scott, J. E., McAbee, K. R., Eastman, M. M., \& Ravosa, M. J. (2014b). Experimental perspective on fallback foods and dietary adaptations in early hominins. Biology Letters, 10(1), 20130789. https://doi.org/10.1098/rsbl.2013.0789

Selba, M. C., Oechtering, G. U., Gan Heng, H., \& DeLeon, V. B. (2019). The Impact of Selection for Facial Reduction in Dogs: Geometric Morphometric Analysis of Canine Cranial Shape. The Anatomical Record, O(ja). https://doi.org/10.1002/ar.24184

Sharir, A., Stern, T., Rot, C., Shahar, R., \& Zelzer, E. (2011). Muscle force regulates bone shaping for optimal load-bearing capacity during embryogenesis. Development, 138(15), 3247-3259. https://doi.org/10.1242/dev.063768

Slizewski, A., Schönau, E., Shaw, C., \& Harvati, K. (2013). Muscle area estimation from cortical bone. The Anatomical Record, 296(11), 1695-1707. https://doi.org/10.1002/ar.22788

Ström, D., Holm, S., Clemensson, E., Haraldson, T., \& Carlsson, G. E. (1988). Gross anatomy of the craniomandibular joint and masticatory muscles of the dog. Archives of Oral Biology, 33(8), 597-604. https://doi.org/10.1016/0003-9969(88)90135-5 
Swiderski, D. L., \& Zelditch, M. L. (2013). The complex ontogenetic trajectory of mandibular shape in a laboratory mouse. Journal of Anatomy, 223(6), 568-580. https://doi.org/10.1111/joa.12118

Taylor, A. B., \& Vinyard, C. J. (2013). The relationships among jaw-muscle fiber architecture, jaw morphology, and feeding behavior in extant apes and modern humans. American Journal of Physical Anthropology, 151(1), 120-134. https://doi.org/10.1002/ajpa.22260

Thomas, R. E. (1979). Temporo-mandibular joint dysplasia and open-mouth jaw locking in a Bassett Hound: a case report. The Journal of Small Animal Practice, 20(11), 697-701. https://doi.org/10.1111/j.1748-5827.1979.tb06684.x

Thomason, J. J. (1991). Cranial strength in relation to estimated biting forces in some mammals. Canadian Journal of Zoology, 69(9), 2326-2333. https://doi.org/10.1139/z91-327

Tomo, S., Hirakawa, T., Nakajima, K., Tomo, I., \& Kobayashi, S. (1993). Morphological classification of the masticatory muscles in dogs based on their innervation. Annals of Anatomy - Anatomischer Anzeiger, 175(4), 373-380. https://doi.org/10.1016/S09409602(11)80047-6

Trut, L. (1999). Early Canid Domestication: The Farm-Fox Experiment: Foxes bred for tamability in a 40-year experiment exhibit remarkable transformations that suggest an interplay between behavioral genetics and development. American Scientist, 87(2), $160-169$.

Trut, L., Oskina, I., \& Kharlamova, A. (2009). Animal evolution during domestication: the domesticated fox as a model. Bioessays, 31(3), 349-360. https://doi.org/10.1002/bies.200800070

Turnbull, W. D. (1970). Mammalian masticatory apparatus, 18(2), 149-356.

Van Valen, L. (1965). The study of morphological integration. Evolution, 19(3), 347-349. https://doi.org/10.1111/j.1558-5646.1965.tb01725.x

Ward, K. A., Caulton, J. M., Adams, J., \& Mughal, M. Z. (2006). Perspective: cerebral palsy as a model of bone development in the absence of postnatal mechanical factors. Journal of musculoskeletal \& neuronal interactions, 6(2), 154-159.

Watt, D. G., \& Williams, C. H. (1951). The effects of the physical consistency of food on the growth and development of the mandible and the maxilla of the rat. American Journal of Orthodontics, 37(12), 895-928.

Weijs, W. A., \& Hillen, B. (1986). Correlations between the cross-sectional area of the jaw muscles and craniofacial size and shape. American Journal of Physical Anthropology, 70(4), 423-431. https://doi.org/10.1002/ajpa.1330700403

Weiner, S., \& Wagner, H. D. (1998). THE MATERIAL BONE: Structure-Mechanical Function Relations. Annual Review of Materials Science, 28(1), 271-298. https://doi.org/10.1146/annurev.matsci.28.1.271

Wiley, D. F., Amenta, N., Alcantara, D. A., Ghosh, D., Kil, Y. J., Delson, E., et al. (2005). Evolutionary morphing. In VIS 05. IEEE Visualization, 2005. (pp. 431-438). Presented at the VIS 05. IEEE Visualization, 2005. https://doi.org/10.1109/VISUAL.2005.1532826 
961 Wolff, J. (1986). The Law of Bone Remodelling. Berlin Heidelberg: Springer-Verlag. doi: https://10.1007/978-3-642-71031-5 
963

964

965

966

967

968

969

970

971

972

973

974

975

976

977

978

979

980

981

982

983

984

985

986

987

988

989

990

991

992

\section{Figure legends}

\section{Fig. 1}

Schematic illustration of the jaw muscles dissected in this study. Muscles in medial to mandible are rendered transparent.

\section{Fig. 2}

Position of the landmarks used in this study and mandible features following Budras (2007), Barone (2010), Evans and DeLahunta (2010). Anatomical landmarks are indicated in red, sliding semi-landmarks of curves are in blue and sliding semi-landmarks on the surface are in green. AM: angle of mandible; B: body of mandible; R : ramus of mandible; con: condyloid process; cor: coronoid process; ang: angular process; is: intermandibular suture; n: mandibular notch; he: head of mandible; ne: condylar neck; vb: ventral border; fos: masseteric fossa; conc: condyloid crest; corc: coronoid crest; manf: mandibular foramen; menf: main mental foramen; can: canine; car: carnassial (M1).

\section{Fig. 3}

First two axes of the PCA describing variation in: A) mandibular shape; B) allometry-free mandibular shape. The mesh of the consensus is represented in white. Illustrations represent the deformations from the consensus to the extreme of the axis in lateral, dorsal and caudal views for PC1 and in lateral view for PC2. Ages are indicated by colors. Beagles are in green and other breed names are indicated following Table 1.

\section{Fig. 4}

PCA describing variation in A) PCSA or B) scaled PCSA of the jaw muscles. Histograms represent the loadings of the original variables on the axes. Dig: Digastric; MS: masseter pars superficialis; MP: masseter pars profunda; ZMA: masseter pars zygomaticomandibularis anterior; ZMP: masseter pars zygomaticomandibularis posterior; SZ: temporalis pars suprazygomatica; TS: temporalis pars superficialis; TP: temporalis pars profunda; P: pterygoids. Ages are indicated by colors. Beagles are in green and other breed names are indicated following Table 1.

\section{Fig. 5}

2-Block Partial Least Square Analyses between mandibular shape and the scaled PCSA of jaw muscles, with muscle vectors and shapes at the minimum and maximum of the PLS axis. 
993

994

995

996

997

998

999

1000

1001

1002

1003

1004

1005

1006

1007

1008

1009

1010

1011

1012

1013

1014

1015

1016

1017

1018

1019

Illustrations represent the deformations from the consensus to the extreme of the axis in lateral, dorsal and caudal views. Dig: Digastric; MS: masseter pars superficialis; MP: masseter pars profunda; ZMA: masseter pars zygomaticomandibularis anterior; ZMP: masseter pars zygomaticomandibularis posterior; SZ: temporalis pars suprazygomatica; TS: temporalis pars superficialis; TP: temporalis pars profunda; P: pterygoids. Ages are indicated by colors. Beagles are in green and other breed names are indicated following Table 1.

\section{Fig. 6}

2-Block Partial Least Square Analyses between the shape of the ramus and the scaled mass of jaw muscles, with muscle vectors and shapes at the minimum and maximum of the PLS axis. Illustrations represent the deformations from the consensus to the extreme of the axis in lateral, dorsal and caudal views. Dig: Digastric; MS: masseter pars superficialis; MP: masseter pars profunda; ZMA: masseter pars zygomaticomandibularis anterior; ZMP: masseter pars zygomaticomandibularis posterior; SZ: temporalis pars suprazygomatica; TS: temporalis pars superficialis; TP: temporalis pars profunda; P: pterygoids. Ages are indicated by colors. Beagles are in green and other breed names are indicated following Table 1.

\section{Fig. 7}

2-Block Partial Least Square Analyses between allometry-free mandibular shape and the scaled PCSA of jaw muscles, with muscle vectors and shapes at the minimum and maximum of the PLS axis. Illustrations represent the deformations from the consensus to the extreme of the axis in lateral, dorsal and caudal views. Dig: Digastric; MS: masseter pars superficialis; MP: masseter pars profunda; ZMA: masseter pars zygomaticomandibularis anterior; ZMP: masseter pars zygomaticomandibularis posterior; SZ: temporalis pars suprazygomatica; TS: temporalis pars superficialis; TP: temporalis pars profunda; P: pterygoids. Ages are indicated by colors. Beagles are in green and other breed names are indicated following Table 1.

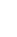


1020

1021

1022

1023

1024

1025

1026

1027

1028

1029

1030

1031

1032

1033

1034

1035

1036

1037

1038

1039

1040

1041

1042

1043

1044

1045

1046

1047

1048

\section{Supplementary material}

The online version of this article contains supplementary material, which is available to authorized users.

\section{Supplementary material Table S1}

Details of the specimen used in this study including raw jaw muscles data and PCSAs.

\section{Supplementary material Table S2}

Origin and insertion of the jaw muscles dissected in this study, after a synthesis of nomenclatures proposed by Schumacher (1961), Turnbull (1970), Ström et al. (1988), Tomo et al. (1993), Christiansen and Adolfssen (2005), Budras (2007), Barone (2010), Evans and DeLahunta (2010), Hung et al. (2010), Druzinsky et al. (2011), Hartstone-Rose et al. (2012), Flahive (2015), Penrose et al. (2016).

\section{Supplementary material Table S3}

Results of the statistical analyses exploring allometries (sheet 1) and the variability (sheet 2) in mandibular shape and muscle data.

\section{Supplementary material Table S4}

Results of the 2-Block Partial Least Square Analyses (sheet 1) and P-values and Z-scores of the comparison tests (sheet 2). S: shape of the mandible; rS: shape of the ramus; a: allometryfree (shape or shape of the ramus); M: mass; PCSA: PCSA; s: scaled (mass or PCSA).

Sigificant results $(\mathrm{p}$-value $<0.05)$ are indicated in bold.

\section{Supplementary Fig. S1}

Distribution of the specimens along the allometric slope with a visualisation of the differences between large and small specimens relative to consensus shape. Ages are indicated by colors. Beagles are in green and other breed names are indicated following Table 1.

\section{Supplementary Fig. S2}

PCA describing variation in A) mass or B) scaled mass of the jaw muscles. Histograms represent the loadings of the original variables on the axes. Dig: Digastric; MS: masseter pars superficialis; MP: masseter pars profunda; ZMA: masseter pars zygomaticomandibularis anterior; ZMP: masseter pars zygomaticomandibularis posterior; SZ: temporalis pars suprazygomatica; TS: temporalis pars superficialis; TP: temporalis pars profunda; P: 
pterygoids. Ages are indicated by colors. Beagles are in green and other breed names are indicated following Table 1.

\section{Supplementary Fig. S3}

2-Block Partial Least Square Analyses between mandibular shape and the PCSA of jaw muscles, with muscle vectors and shapes at the minimum and maximum of the PLS axis. Illustrations represent the deformations from the consensus to the extreme of the axis in lateral, dorsal and caudal views. Dig: Digastric; MS: masseter pars superficialis; MP: masseter pars profunda; ZMA: masseter pars zygomaticomandibularis anterior; ZMP: masseter pars zygomaticomandibularis posterior; SZ: temporalis pars suprazygomatica; TS: temporalis pars superficialis; TP: temporalis pars profunda; P: pterygoids. Ages are indicated by colors. Beagles are in green and other breed names are indicated following Table 1.

\section{Supplementary Fig. S4}

2-Block Partial Least Square Analyses between mandibular shape and the mass of jaw muscles, with muscle vectors and shapes at the minimum and maximum of the PLS axis. Illustrations represent the deformations from the consensus to the extreme of the axis in lateral, dorsal and caudal views. Dig: Digastric; MS: masseter pars superficialis; MP: masseter pars profunda; ZMA: masseter pars zygomaticomandibularis anterior; ZMP: masseter pars zygomaticomandibularis posterior; SZ: temporalis pars suprazygomatica; TS: temporalis pars superficialis; TP: temporalis pars profunda; P: pterygoids. Ages are indicated by colors. Beagles are in green and other breed names are indicated following Table 1.

\section{Supplementary Fig. S5}

2-Block Partial Least Square Analyses between the shape of the ramus and the PCSA of jaw muscles, with muscle vectors and shapes at the minimum and maximum of the PLS axis. Illustrations represent the deformations from the consensus to the extreme of the axis in lateral, dorsal and caudal views. Dig: Digastric; MS: masseter pars superficialis; MP: masseter pars profunda; ZMA: masseter pars zygomaticomandibularis anterior; ZMP: masseter pars zygomaticomandibularis posterior; SZ: temporalis pars suprazygomatica; TS: temporalis pars superficialis; TP: temporalis pars profunda; P: pterygoids. Ages are indicated by colors. Beagles are in green and other breed names are indicated following Table 1.

\section{Supplementary Fig. S6}


2-Block Partial Least Square Analyses between the shape of the ramus and the mass of jaw muscles, with muscle vectors and shapes at the minimum and maximum of the PLS axis. Illustrations represent the deformations from the consensus to the extreme of the axis in lateral, dorsal and caudal views. Dig: Digastric; MS: masseter pars superficialis; MP: masseter pars profunda; ZMA: masseter pars zygomaticomandibularis anterior; ZMP: masseter pars zygomaticomandibularis posterior; SZ: temporalis pars suprazygomatica; TS: temporalis pars superficialis; TP: temporalis pars profunda; P: pterygoids. Ages are indicated by colors. Beagles are in green and other breed names are indicated following Table 1.

\section{Supplementary Fig. S7}

2-Block Partial Least Square Analyses between mandibular shape and the scaled mass of jaw muscles, with muscle vectors and shapes at the minimum and maximum of the PLS axis. Illustrations represent the deformations from the consensus to the extreme of the axis in lateral, dorsal and caudal views. Dig: Digastric; MS: masseter pars superficialis; MP: masseter pars profunda; ZMA: masseter pars zygomaticomandibularis anterior; ZMP: masseter pars zygomaticomandibularis posterior; SZ: temporalis pars suprazygomatica; TS: temporalis pars superficialis; TP: temporalis pars profunda; P: pterygoids. Ages are indicated by colors. Beagles are in green and other breed names are indicated following Table 1.

\section{Supplementary Fig. S8}

2-Block Partial Least Square Analyses between the shape of the ramus and the scaled PCSA of jaw muscles, with muscle vectors and shapes at the minimum and maximum of the PLS axis. Illustrations represent the deformations from the consensus to the extreme of the axis in lateral, dorsal and caudal views. Dig: Digastric; MS: masseter pars superficialis; MP: masseter pars profunda; ZMA: masseter pars zygomaticomandibularis anterior; ZMP: masseter pars zygomaticomandibularis posterior; SZ: temporalis pars suprazygomatica; TS: temporalis pars superficialis; TP: temporalis pars profunda; P: pterygoids. Ages are indicated by colors. Beagles are in green and other breed names are indicated following Table 1.

\section{Supplementary Fig. S9}

2-Block Partial Least Square Analyses between between allometry-free mandibular shape and the scaled mass of jaw muscles, with muscle vectors and shapes at the minimum and maximum of the PLS axis. Illustrations represent the deformations from the consensus to the extreme of the axis in lateral, dorsal and caudal views. Dig: Digastric; MS: masseter pars 
superficialis; MP: masseter pars profunda; ZMA: masseter pars zygomaticomandibularis

1111 anterior; ZMP: masseter pars zygomaticomandibularis posterior; SZ: temporalis pars

1112 suprazygomatica; TS: temporalis pars superficialis; TP: temporalis pars profunda; P:

1113 pterygoids. Ages are indicated by colors. Beagles are in green and other breed names are

1114 indicated following Table 1.

\section{Supplementary Fig. S10}

1116 2-Block Partial Least Square Analyses between the allometry-free shape of the ramus and the 1117 scaled mass of jaw muscles, with muscle vectors and shapes at the minimum and maximum of 1118 the PLS axis. Illustrations represent the deformations from the consensus to the extreme of the 1119 axis in lateral, dorsal and caudal views. Dig: Digastric; MS: masseter pars superficialis; MP: 1120 masseter pars profunda; ZMA: masseter pars zygomaticomandibularis anterior; ZMP:

1121 masseter pars zygomaticomandibularis posterior; SZ: temporalis pars suprazygomatica; TS:

1122 temporalis pars superficialis; TP: temporalis pars profunda; P: pterygoids. Ages are indicated 1123 by colors. Beagles are in green and other breed names are indicated following Table 1. 